\title{
POLÍTICAS DE AVALIAÇÃO \\ DA EDUCAÇÃO SUPERIOR BRASILEIRA: \\ PROVÃO, SINAES, IDD, CPC, IGC E...OUTROS ÍNDICES
}

\author{
Marlis Morosini Polidori*
}

Recebido em: 31 de outubro de 2008

Aprovado em: 27 de fevereiro de 2009

* Dra. em Ciências da Educação pela Universidade do Porto (Portugal). Docente e Pesquisadora do Centro Universitário Metodista IPA/POA. E-mail: mpolidori@metodistadosul.edu.br

Resumo: Este artigo busca discutir o desenvolvimento do processo de avaliação da educação superior brasileira no que diz respeito à sua concepção, considerando a trajetória percorrida e as ações que estão sendo implantadas no país, principalmente no ano de 2008 e em "nome” do SINAES. Os novos indicadores inseridos no processo avaliativo estão ferindo, e de forma severa, o Sistema de Avaliação que tem como finalidade ser processual, formativo, emancipatório e que busca a melhoria da qualidade da educação superior no Brasil.

Palavras-chave: Avaliação. SINAES. Políticas educacionais.

\section{HIGHER EDUCATION EVALUATION POLICIES IN BRAZIL: PROVÃO, SINAES, IDD, CPG, IGC AND... OTHER PERFORMANCE INDICATORS}

\begin{abstract}
This article discusses the development of the evaluation process in Brazilian higher education regarding its conception, considering the path covered and the actions that are being implanted in the country, especially in the year 2008, "in the name of" SINAES. The new indicators inserted in the evaluation process are severely harming the Evaluation System that has the purpose of being process based, formative and emancipatory, seeking the improvement of higher education in Brazil.
\end{abstract}

Keywords: Evaluation. SINAES. Educational policies.

\section{Introdução}

O processo de avaliação da educação superior no Brasil apresenta uma trajetória bastante rica e, inclusive, inovadora no que diz respeito à sua proposta de considerar o processo na sua totalidade.

As duas últimas décadas apresentam mudanças radicais no seu formato, principalmente em relação à sua concepção. De uma avaliação totalitária e que primava pelo ranqueamento, passou para um processo que respeita as diversidades e as especificidades das Instituições de Educação Superior (IES), momento em que foi instituído o Sistema Nacional de Avaliação da Educação Superior, o SINAES. 
No entanto, um novo fenômeno vem ocorrendo no ano de 2008 quando, no desenvolvimento desse Sistema, o qual evidencia e considera todos os elementos que o compõem, são criados e emitidos indicadores que pretendem elaborar rankings das "melhores" IES do país, utilizando-se somente o elemento da avaliação realizada pelos estudantes, o Exame Nacional de Desempenho dos Estudantes - ENADE.

Este artigo, a partir do histórico do desenvolvimento dos processos de avaliação da educação superior do Brasil nas últimas duas décadas, busca mapear e discutir as novas ações apresentadas pelo governo que, em nosso entendimento, fere, profundamente, a concepção do atual Sistema de Avaliação da Educação Superior no país.

\section{O processo de avaliação da educação superior} (de 1995 a 2003)

O governo Fernando Henrique Cardoso (FHC) compreendeu o período de 1995 a 2002 e teve como seu Ministro da Educação o economista Paulo Renato Souza. Em 1998, o governo FHC fez a Reforma de Estado, na qual a maioria dos setores de infra-estrutura que davam sustentação ao Estado brasileiro foi privatizada ou terceirizada. Esses setores, de serviços sociais e científicos, compreendiam escolas, universidades, centros de pesquisa, creches, hospitais, entre outros. Essa ação acabou por privatizar ou conceder ao setor privado a execução de funções e serviços públicos, incluindo-se a educação superior.

Nesta mesma linha, durante esse período, ocorreram várias influências externas sobre a educação superior mundial. O Banco Mundial, em 1995, elaborou o documento "La enseñanza superior: las lecciones derivadas de la experiência”, no qual apresenta uma moldura da crise da educação superior e defende reformas que viriam a garantir maior eficiência, qualidade e eqüidade.

A UNESCO, também um órgão internacional, publicou documentos com a perspectiva de definir políticas para a educação superior. O principal deles foi “La educacion superior em el siglo XXI: vision y acción”, apresentado na Conferência Mundial sobre a Educação Superior, em Paris, em 1998. Segundo esse documento, a educação superior de qualidade não pode estar dissociada da avaliação e da regulação, considerando, ainda, como fundamentais, os seguintes fatores: a cultura da avaliação, da emancipação, da autonomia da responsabilidade e da prestação de contas.

Outro documento editado pelo Banco Mundial, em 2004, intitulado "Higher Education in developing countries: peril and promise”, busca esclarecer o 
equívoco de priorizar a educação básica em detrimento da educação superior e atribui ao Estado o papel de supervisor, o que veio a fortalecer o estabelecimento de políticas de avaliação da educação superior em todo o mundo.

No Brasil, no período do Ministro Paulo Renato, dentre as principais ações estão a criação do Exame Nacional do Ensino Médio (ENEM), do Fundo de Manutenção e Desenvolvimento do Ensino Fundamental e de Valorização do Magistério (FUNDEF) e da Bolsa-Escola.

Em relação à educação superior, os principais elementos criados estavam fundamentados em uma proposta de avaliação que seguia, inclusive, as orientações internacionais de transformar o Estado de um órgão controlador para um regulador utilizando-se de sistemas de avaliação ${ }^{1}$.

Neste mesmo governo, instituiu-se, em 1996, através do Decreto 2026, um mecanismo de avaliação denominado de Exame Nacional de Cursos (ENC), conhecido, mais tarde, como Provão, o qual existiu de 1996 a 2003. O Provão foi considerado um instrumento indicador de eficácia da IES, utilizando os resultados do desempenho dos alunos. Isto é, por meio de uma prova de conhecimentos realizada pelos discentes, a Instituição de Ensino Superior recebia um conceito que variava de "A" a "E", sendo o conceito "A" considerado o

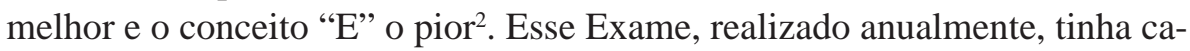
ráter obrigatório para todos os estudantes concluintes dos cursos de graduação, condicionando sua realização ao recebimento do diplomas pelos alunos.

Junto com o provão, era realizado pelo o $\mathrm{INEP}^{3}$, órgão responsável pela aplicação do Exame, um questionário socioeconômico e cultural. Em 1996, na primeira edição do Provão, participaram os Cursos de Administração, Direito e Engenharia Civil. Posteriormente, a cada ano eram adicionados novos cursos

1 O Modelo de Controle Estatal caracteriza-se por políticas, segundo as quais as universidades são obrigadas a seguirem padrões preestabelecidos pelo governo. Neste modelo, é desenvolvido um controle detalhado de todos os aspectos relacionados com a educação superior e apóia-se no chamado Princípio da Homogeneidade Legal. No modelo do Controle pelo Estado são necessários extensos mecanismos de regulação e um controle a priori baseado na abundante publicação de leis, decretos, portarias, circulares e pareceres. O Modelo de Supervisão Estatal resulta do reconhecimento, por parte do Estado, da dificuldade e ineficiência do controle a priori de um sistema de educação superior que se massificou, que se tornou imensamente complexo e que está em constante mutação. A este reconhecimento associou-se uma certa idéia de que algum elemento de competição "tipo mercado" levaria as instituições a terem um comportamento mais eficaz e a responderem melhor às demandas da sociedade (NEAVE; VAN VUGHT, 1994). O fato de o empregador principal ter deixado de ser o Estado permitiu descartar este princípio (homogeneidade legal) que veio a ser substituído pelo do Estado Avaliativo. Este modelo de supervisão caracteriza-se por possuir uma baixa intervenção nas decisões diárias das instituições, pois estas possuem uma autonomia ampla, e o governo centra-se numa atividade de dirigir, supervisionar e avaliar as performances das instituições numa fase posterior. (AMARAL; MAGALHÃES, 1999)

2 Nestes conceitos, o A correspondia a $12 \%$ das melhores marcas obtidas, o B a $18 \%$, o C a $40 \%$, o D a $18 \%$ e o $\mathrm{E}$ a $12 \%$.

3 Instituto Nacional de Estudos e Pesquisas Educacionais Anísio Teixeira. 
e, em 2003, o Provão ou o Exame Nacional de Cursos chegou a contemplar 26 áreas de conhecimento ${ }^{4}$.

O Provão acabou sendo considerado um grande marco na educação superior brasileira, apesar de todas as críticas que sofreu. O então Ministro da Educação dizia que "O Provão é um divisor de águas: o descaso de antes e a universidade do futuro". As duas principais questões criticadas nesse sistema foram: a) o fato de se utilizar o resultado do desempenho dos alunos para conceituar as Instituições de Educação Superior (IES) e, b) esse resultado ser apresentado em forma de rankings. Nesta circunstância, o ranking trazia as "melhores” e as "piores" IES, segundo esta metodologia. No entanto, foi possível verificar mais tarde, após estudo feito pelo próprio INEP, que nem sempre o conceito "A" de uma determinada área significava um valor maior que um conceito "E" de outra área. Esse estudo acabou por demonstrar que os rankings apresentados ao longo da existência do Provão não eram verdadeiros.

Não eram verdadeiros na medida em que os conceitos somente eram publicados de forma relativa. Na divulgação dos resultados do Provão de 2003, o INEP, na gestão que assumiu a partir desta data, apresentou os resultados de forma relativa e absoluta com o objetivo de: "(1) contribuir para desmistificar o significado dos conceitos relativos e (2) preservar aqueles cursos e instituições de qualidade - cursos e instituições que, sabidamente, não podem ter a sua qualidade aferida somente por um exame aplicado aos alunos.” (INEP, 2003)

Neste sentido, o relatório apresentou o equívoco pelo qual a educação superior brasileira vinha passando há oito anos: de considerar os conceitos obtidos pelos cursos como um único indicador de qualidade. Conforme consta no Resumo Técnico (INEP, 2003): “[...] os resultados deste ano revelam que a nota 46,3 em Administração é $A$; já a nota 49,7 em Odontologia é $D ; 50,0$ em Engenharia Civil é $A$; já 52,3 em Fonoaudiologia é $C$; 41,8 em Engenharia Elétrica é $B$; já 44,1 em Agronomia é A; 29,4 em Matemática é $A$; já em Pedagogia 32,0 é D; e assim por diante".

Em complementação ao Provão, o governo introduziu outro mecanismo denominado Avaliação das Condições de Oferta (ACO), cuja proposta era avaliar os cursos e as Instituições de Educação Superior. Ainda, havia a proposta de inserir o processo de avaliação das IES para credenciamento e recredenciamento, no caso de instituições privadas.

4 Administração, Agronomia, Arquitetura e Urbanismo, Biologia, Ciências Contábeis, Direito, Economia, Enfermagem, Engenharia Civil, Engenharia Elétrica, Engenharia Mecânica, Engenharia Química, Farmácia, Física, Fonoaudiologia, Geografia, História, Jornalismo, Letras, Matemática, Medicina, Medicina Veterinária, Odontologia, Pedagogia, Psicologia e Química. 
No entanto, somente o Provão foi o instrumento utilizado para a base de estruturação de políticas educativas. Os demais foram sendo desenvolvidos pontualmente e, principalmente, para atender à legislação referente à autorização, reconhecimento, renovação de reconhecimento de cursos de graduação e credenciamento e recredenciamento de IES. (POLIDORI; MARINHO-ARAÚJO; BARREYRO, 2006)

Um dos elementos considerados absolutamente nocivos ao sistema de educação superior do país é a expansão desordenada, proporcionada pelo governo Paulo Renato. Durante os anos de 1996 a 2003, ocorreu um grande crescimento no que se refere à criação de novas Instituições de Educação Superior. Como por exemplo, de 894 IES que existiam em 1995, em 2003 este número passou a ser de 1.859; de 1.759.703 matrículas no ano de 1995, em 2003 o número alcançou 3.887.022. (INEP, 2004)

A discussão não está no aumento de matrículas e, inclusive, de IES no país, já que isso é uma necessidade da realidade educacional brasileira. É, sim, preciso proporcionar formas de aumentar o número de estudantes, uma vez que o índice atual no Brasil de indivíduos, entre 18 e 24 anos, que freqüentam o ensino superior é de cerca de $13 \%$. No entanto, a discussão está na forma como ocorre ou como ocorreu essa expansão que privilegiou o mercado como grande regulador. Esse processo possibilitou a instalação de várias IES e cursos com baixa qualidade no país.

Em 1997, o Decreto 2306 criou novas figuras jurídicas para as Instituições de Educação Superior, o centro universitário e as faculdades integradas, buscando, com isso, a ampliação, a diversificação e a organização institucional do sistema de educação superior e assim compor o quadro junto com as universidades.

Na continuidade, em 1998, a Resolução 02 estabeleceu indicadores para comprovar a produção intelectual institucionalizada para fins de credenciamento de universidades. Esse passou a ser o único documento que rege as exigências para a existência de uma universidade.

Em 2001, foi aprovado o Plano Nacional de Educação (PNE), através da Lei 10.172/2001, e, neste mesmo ano, entrou em vigor o Decreto 3860 que mudou as regras de organização e avaliação de cursos e de IES no Brasil. Na seqüência, a antiga Avaliação de Condições de Oferta (ACO) passou a ser denominada de Avaliação das Condições de Ensino (ACE).

5 Nos países da OCDE, essa porcentagem é, em média, de 30\%. No Japão (90\%), na Bélgica (80\%), na França (79\%), em Portugal (66\%), na República Checa (63\%), na Hungria (62\%), na Suécia (61\%), na Coréia do Sul (60\%), na Grécia (56\%) e na Nova Zelândia (50\%). (OCDE, 2007) 
Conforme já mencionado, essas foram as avaliações realizadas para reconhecimento e renovação de reconhecimento de cursos e credenciamento e recredenciamento de IES. Como complementação, e se utilizando da Lei 9394/96 (LDB), a Portaria 1465/01 estabeleceu que a SESu ${ }^{6}$ solicitaria ao INEP a realização de avaliação nas IES em processo de recredenciamento.

Em relação à evolução do desenvolvimento do processo avaliativo em âmbito nacional, considera-se que houve uma divisão em quatro ciclos, sendo que o período de oito anos do governo FHC e de Paulo Renato caracterizou-se como terceiro ciclo. Nesse sentido, os ciclos assim se apresentam:

- Primeiro ciclo (1986 a 1992) - várias iniciativas de organização de um processo de avaliação, e a existência de avaliações isoladas no país não se constituindo em uma avaliação de caráter nacional (PARU, GERES);

- Segundo ciclo (1993 a 1995) - denominado de formulação de políticas. Instalação do Programa de Avaliação Institucional das Universidades Brasileiras (PAIUB);

- Terceiro ciclo (1996 a 2003) - denominado de consolidação ou implementação da proposta governamental. Ocorreu o desenvolvimento do Exame Nacional de Cursos (ENC), o Provão, e o da Avaliação das Condições de Oferta (ACO), a qual passou, posteriormente, a ser chamada de Avaliação das Condições de Ensino (ACE). Por fim, houve, ainda, algumas Portarias para regulamentarem e organizarem a avaliação das IES;

- Quarto ciclo (2003 a atual) - denominado de construção da avaliação emancipatória, com a implantação do SINAES ${ }^{7}$, numa proposta de se desenvolver uma avaliação formativa e que considerasse as especificidades das IES do país. (FELIX, 2008; FONSECA, 2007)

\section{A continuidade do processo de avaliação da educação superior (2003 a 2008)}

Em 2003, ocorreu a troca de Presidente no país, tendo sido eleito Luiz Inácio Lula da Silva (Lula). No início do governo Lula, foi Ministro da Educação o atual Senador Cristovam Buarque, cujo exercício compreendeu o período de 1\%/1/2003 a 27/1/2004. A seguir, assumiu o Ministro Tarso Genro, o qual permaneceu no cargo de 27/1/2004 a 29/7/2005. Após, o Ministério da Educação

6 SESu- Secretaria da Educação Superior.

7 SINAES - Sistema Nacional de Avaliação da Educação Superior. 
foi assumido pelo braço direto do ministro Tarso Genro, Fernando Hadaad, que permanece no cargo até a atualidade.

Foi no início deste período que foi instituído o Sistema Nacional de Avaliação da Educação Superior (SINAES). O SINAES começou a ser criado a partir da constituição da Comissão Especial de Avaliação do Ensino Superior (CEA), constituída por representantes das IES, de membros do Ministério da Educação e da UNE. Essa proposta, em 2004, transformou-se em Lei (10.861), instituindo o Sistema.

O objetivo do SINAES é assegurar o processo nacional de avaliação da IES, de cursos de graduação e do desempenho acadêmico dos estudantes, buscando a melhoria da qualidade do ensino superior no país.

Os resultados da avaliação devem subsidiar os processos de regulação e supervisão da educação superior que compreendem as ações de autorização, reconhecimento e renovação de reconhecimento de cursos de graduação, e credenciamento e recredenciamento de IES.

Sendo assim, o SINAES apresenta três grandes pilares: (1) avaliação institucional; (2) avaliação de cursos e (3) avaliação do desempenho dos estudantes. Esses pilares são atendidos pelos processos de avaliação in loco para os itens um e dois, e complementados pela organização e avaliação interna de cada IES. O pilar três é atendido pela realização do Exame Nacional de Desempenho dos Estudantes, o ENADE.

A coordenação e a supervisão do SINAES estão a cargo da Comissão Nacional de Avaliação da Educação Superior (CONAES), criada para atender a esta demanda, e o sistema é operacionalizado pelo INEP em conjunto com a SESu.

Em relação às IES, cada uma, a partir de exigência de Lei do SINAES, criou seu órgão de organização e coordenação da avaliação desenvolvida internamente, denominada de Comissão Própria de Avaliação (CPA).

É importante evidenciar que o SINAES busca reconhecer a diversidade do sistema de educação superior do país, respeitar a identidade, a missão e a história das IES, entender que essas devem ser avaliadas globalmente e ainda buscar a continuidade do processo avaliativo.

O SINAES está em vigor desde 2004 e foi implantado como um processo completamente diferenciado daquele que vinha sendo realizado nos últimos oito anos no Brasil. O primeiro embate que o Sistema sofreu foi, justamente, a reação dos docentes da educação superior, principalmente devido ao elemento novo que estava sendo apresentado pelo governo. Apesar de o Sistema ter sido criado a partir de uma Comissão bastante diversa (CEA), quando do momento da divulgação em grande escala para a comunidade acadêmica do país, as reações foram bastante adversas. 
Esse período abrangeu, além do tempo necessário para se conhecer o novo, a compreensão de uma nova proposta aplicada por um novo governo, o governo Lula.

A proposta do SINAES compreende a necessidade das IES passarem por um ciclo completo de avaliação. Esse ciclo envolve os três pilares do Sistema, ou seja, a avaliação institucional, a avaliação de cursos e a avaliação de desempenho dos estudantes. No entanto, o ciclo desse Sistema não pode ser considerado como uma dinâmica linear. Cada pilar compreende vários estágios e atuações que se diferem de IES para IES. Aliás, este é um dos grandes princípios do SINAES: "respeitar as diferenças e as especificidades de cada IES".

Neste sentido, a conclusão ou o fechamento desse ciclo exigiu uma regulamentação suplementar pela parte dos órgãos governamentais para dar o movimento necessário ao Sistema.

Todavia, ocorreram várias alterações no Ministério da Educação, gerando mudanças nos órgãos operacionais e regulatórios como o INEP e a SESu. Com a passagem do cargo de Ministro, de Tarso Genro para Fernando Hadaad, a partir de 2005, houve uma modificação na dinâmica do processo. Na sua continuidade, em 2007, os dirigentes que estavam à frente desse processo de avaliação da educação superior foram permutados, e o processo, atualmente, vem apresentando problemas de continuidade, o que interfere, inclusive, na finalização da primeira etapa do Sistema.

Esta nova fase governamental apresentou, no ano de 2008, a instalação de dois novos indicadores no contexto da educação superior brasileira. O primeiro deles, denominado Conceito Preliminar de Curso (CPC), foi instituído pela Portaria Normativa $\mathrm{n}^{\circ} 4$ de 5 de agosto de 2008 e veio a compor o cenário de uma forma díspar ao Sistema.

O CPC é formado por três elementos: os insumos que lhe são atribuídos, $30 \%$ da nota final; o ENADE, com atribuição de $40 \%$; e o IDD $^{8}$ com $30 \%$. Esses insumos são compostos pelas seguintes informações: infra-estrutura e instalações físicas, com peso 10,2; recursos didático-pedagógicos, com 27,2 de peso; corpo docente, considerando-se a titulação, peso de 38,9 ; e o regime de trabalho com o peso de 23,8.

É importante evidenciar que uma parte dessas informações é retirada dos questionários preenchidos pelos alunos que participam do ENADE e a outra - a que diz respeito ao corpo docente - do Sistema de Cadastro dos Docentes que todas as IES são obrigadas a preencher.

8 O IDD é a diferença entre o desempenho médio do concluinte de um curso e o desempenho médio estimado para os concluintes desse mesmo curso e representa quanto cada curso se destaca da média. $\mathrm{O}$ curso pode ficar acima ou abaixo do que seria esperado para ele baseando-se no perfil de seus estudantes. 
É informado, ainda, que os cursos que obtiverem conceito um e dois nesta “avaliação” receberão, obrigatoriamente, a visita da comissão de avaliação. Para os cursos com conceito três e quatro, a avaliação será opcional, e os cursos com conceito cinco terão suas Portarias de renovação de reconhecimento geradas automaticamente pela SESu ou SETEC, de acordo com a natureza do curso.

Facilmente é possível perceber a distorção da composição deste indicador, se observadas algumas considerações. Primeiro, o SINAES é composto por três pilares, como já foi dito, sendo que um desses pilares é constituído pelo ENADE e, dentro da filosofia do Sistema, é utilizado para compor o parecer final de uma IES e de seus cursos. A partir do momento em que é considerado um desses pilares como o único elemento definidor de qualidade daquele curso ou IES, está ocorrendo uma transgressão do Sistema atual de avaliação.

Nesta estrutura, são retiradas informações do processo ENADE em cerca de $90 \%$, tendo em vista que $40 \%$ são do ENADE, 30\% do IDD que é calculado a partir do ENADE, e dos insumos que compreendem os outros $30 \%$, as informações referentes à infra-estrutura e instalações físicas e recursos didáticopedagógicos são obtidas através do questionário preenchido pelos alunos que participam do ENADE.

Apresenta-se, aqui, um grande equívoco em termos de aplicabilidade do SINAES na sua proposta conceitual a partir do uso de um único pilar do Sistema como o definidor de qualidade da educação superior oferecida pelas IES.

Ainda há um segundo indicador criado, intitulado de Índice Geral de Cursos da Instituição de Educação Superior (IGC), instituído pela Portaria Normativa $\mathrm{n}^{\mathrm{o}} 12$ de 5 de setembro de 2008. Esse indicador, de acordo com sua Portaria, consolida informações relativas aos cursos superiores constantes dos cadastros, censo e avaliações oficiais disponíveis no Instituto Nacional de Estudos e Pesquisas Anísio Teixeira (INEP) e na Coordenação de Aperfeiçoamento de Pessoal de Nível Superior (CAPES). Ainda, é informado que o cálculo deste Índice será divulgado anualmente pelo INEP.

O IGC irá se utilizar da média ponderada dos Conceitos Preliminares de Cursos (CPC), sendo a ponderação determinada pelo número de matrículas em cada um dos cursos de graduação correspondentes (Inciso I), e da média ponderada das notas dos programas de pós-graduação, obtidas a partir da conversão dos conceitos fixados pela CAPES, sendo a ponderação baseada no número de matrículas em cada um dos cursos ou programas de pós-graduação strictu sensu correspondente (Inciso II). A Portaria evidencia nos dois primeiros parágrafos do Artigo $2^{\circ}$ que a ponderação levará em conta a distribuição dos alunos da IES entre os diferentes níveis de ensino (graduação, mestrado e doutorado) e 
que, nas instituições sem cursos ou programas de pós-graduação avaliados pela CAPES, o IGC será calculado na forma do inciso I.

Ainda, a Portaria diz que esse Índice será utilizado como referencial orientador das comissões de avaliação institucional.

Neste momento, a situação agrava-se ainda mais, tendo em vista o cenário da educação superior brasileira em que, segundo o Censo 2006 (INEP, 2007), o país possui 2.213 IES, sendo 2.036 Faculdades e 177 Universidades. De acordo com a legislação brasileira da educação superior, somente as universidades têm como finalidade e missão oferecer à sociedade ensino, pesquisa e extensão de forma indissociável; as demais IES (faculdades e centro universitários) devem oferecer um ensino superior de excelência, não possuindo a exigência de oferecer pós-graduação strictu sensu, isto é, mestrado e doutorado. Este é o elemento considerado no segundo momento de cálculo do IGC, ou seja, das 2.213 IES, somente 177 oferecem mestrado e doutorado - melhor dizendo deveriam oferecer, uma vez que existe o conhecimento de que há instituições universitárias que não possuem programa strictu sensu, apesar de serem universidades. Em última instância, tem-se um indicador nacional que contempla cerca de $8 \%$ das IES do país. Importante evidenciar que estamos falando em qualidade da educação superior brasileira na sua totalidade.

Esses indicadores, CPC e IGC, buscam concentrar, num único momento, informações de um único "pilar” do Sistema Nacional de Avaliação da Educação Superior (SINAES), o ENADE, as informações sobre os cursos e a IES, classificando-os e tendo como resultado um ranqueamento.

Como complementação de tal ação governamental - porque ultrapassou a esfera de política de Estado - está sendo criado um novo instrumento de avaliação de cursos que visa atender às demandas dos indicadores. Contudo, um último instrumento de avaliação dos cursos de graduação foi divulgado pelo INEP em setembro do corrente ano, o qual já aborda o indicador CPC.

É possível verificar que está ocorrendo uma espécie de atropelo das ações ministeriais. Há a impressão de que após a divulgação de orientações e determinações algo foi esquecido. Então, informa-se à comunidade acadêmica (quando isto ocorre, porque a maioria das informações atualmente obtidas em relação à educação superior do país passa por um processo de dedução a partir de informações constantes no site) que existe outro indicador sendo lançado no ambiente da educação superior.

Somente para ilustrar, este último instrumento de avaliação institucional (out/2008) divulgado estabelece a escala de um a cinco (escala do SINAES), em que o conceito 1 significa "Quando os indicadores da dimensão avaliada 
configuram um quadro MUITO AQUÉM do que expressa o referencial mínimo de qualidade" e o conceito cinco significa "Quando os indicadores da dimensão avaliada configuram um quadro MUITO ALÉM do que expressa o referencial mínimo de qualidade". Todavia, o que significa "muito além" e "muito aquém" e, ainda, qual o significado ou mensuração para "referencial mínimo de qualidade”? Onde estão estabelecidos esses critérios? As expressões “muito além” e "muito aquém" estão muito além da possibilidade de estabelecer um juízo de valor às questões que estão sendo abordadas.

Numa avaliação formativa ${ }^{9}$, o produto passa a ser apenas um componente do complexo processo da avaliação. Está direcionado à melhora do objeto e à transformação da realidade e do contexto em que este se encontra. O processo metodológico deste modelo de avaliação acontece com produção constante de juízos de valor do avaliador, a respeito do que está sendo avaliado (DIAS SOBRINHO, 2000). Logo, esses juízos de valor têm a intenção de transformação. A sua preocupação está no desenvolvimento da avaliação e não no resultado produzido.

Ainda, para Ribeiro e Costa (2002), a avaliação institucional ${ }^{10}$ parte de uma construção coletiva de questionamentos e hipóteses. É uma resposta ao desejo de ruptura das "mesmices", colocando em movimento, estudos, análises, reflexões e juízo de valor que tenham força de transformação na qualidade da instituição e no seu contexto, na melhoria de processos e das relações psicossociais.

Nesse sentido, a avaliação institucional usa a obtenção de dados quantitativos e qualitativos sobre estudantes, professores, estrutura organizacional dos recursos físicos e materiais, as práticas de gestão, a produtividade dos cursos, e dos professores entre outros com o objetivo de emitir juízo valorativo e tomar decisões em relação ao desenvolvimento da instituição. (POLIDORI et al, 2008)

Como é possível desenvolver esse papel, isto é, inserir-se na complexidade deste processo numa realidade em que os avaliadores das comissões precisam emitir juízos de valor entre "muito além” e "muito aquém”? E, ainda, considerando um "referencial mínimo de qualidade”? Quantos mais indicadores serão lançados no "mercado acadêmico" com o objetivo de se obter um produto final, desconsiderando, no entanto, completamente o seu processo? Ou seja, desconsiderando o SINAES, sistema de avaliação da educação superior em vigor no país e estabelecido por lei.

9 Desenvolver uma avaliação formativa é a proposta do SINAES.

10 Avaliação esperada de ser desenvolvida no contexto e na complementaridade do SINAES. 


\section{REFERÊNCIAS}

AMARAL, Alberto; MAGALHÃES. Antonio. On markets, autonomy and regulation: the Janus Head Revisited. Portugal: Cipes, 1999.

BANCO MUNDIAL. Higher education in developing countries: peril and promise. [s.l.]: [s.n.], 2004.

BANCO MUNDIAL. La enseñanza superior: las lecciones derivadas de la experiencia. [s.l.]: [s.n.], 1995.

BRASIL. Decreto $\mathbf{n}^{\mathbf{0}}$. 2026, de 10 de outubro de 1996. Estabelece procedimentos para o processo de avaliação dos cursos e instituições de ensino superior. Brasília, DF.

BRASIL. Decreto $\mathbf{n}^{\mathbf{0}}$. 2306, de 19 de agosto de 1997. Regulamenta, para o Sistema Federal de Ensino, as disposições contidas no art. 10 da Medida Provisória ${ }^{\circ}$ 1.477-39, de 8 de agosto de 1997, e nos arts. 16, 19, 20, 45, 46 e $\S 1^{\circ}, 52$, parágrafo único, 54 e 88 da Lei n ${ }^{\circ} 9.394$, de 20 de dezembro de 1996, e dá outras providências. Brasília, DF.

BRASIL. Decreto no ${ }^{\mathbf{~}} \mathbf{3 8 6 0}$, de 09 de julho de 2001. Dispõe sobre a organização do ensino superior, a avaliação de cursos e instituições, e dá outras providências.Brasília, DF.

BRASIL. Decreto no ${ }^{\mathbf{}}$. 5773, de 09 de maio de 2006. Dispõe sobre o exercício das funções de regulação, supervisão e avaliação de Instituições de educação e cursos superiores de graduação e sequenciais no sistema federal de ensino. Brasília, DF.

BRASIL. Instrumento de avaliação dos cursos de graduação. Brasília: MEC/INEP/DAES, set 2008.

BRASIL. Instrumento de avaliação institucional externa. Brasília: MEC/ INEP/DAES, out 2008.

BRASIL. Lei 10.172, de 09 de janeiro de 2001. Aprova o Plano Nacional de Educação e dá outras providências. Brasília, DF.

BRASIL. Lei no . 10.861, de 14 de abril de 2004. Institui o Sistema Nacional de Avaliação da Educação Superior - SINAES. Diário Oficial [da]

República Federativa do Brasil, Brasília, DF, 20 mar 1996c. Seção 1, p. 4686. 
BRASIL. Lei no ${ }^{\mathbf{.}} \mathbf{9 3 9 4}$, de 20 de Dezembro de 1996. Estabelece as diretrizes e bases da educação nacional. Brasília, DF.

BRASIL. Nota técnica: cálculo do conceito preliminar de cursos de graduação. Brasília: MEC/INEP, 2008.

BRASIL. Nota técnica: cálculo do índice geral de cursos. Brasília: MEC/ INEP, 2008.

BRASIL. Portaria 1465, de 12 de julho de 2001. Dispõe sobre a organização do ensino superior, a avaliação de cursos e instituições, e dá outras providências.Brasília, DF.

BRASIL. Portaria Normativa $\mathbf{n}^{\mathbf{0}}$ - 4, de 5 de agosto de 2008. Regulamenta a aplicação do conceito preliminar de cursos superiores, para fins dos processos de renovação de reconhecimento respectivos, no âmbito do ciclo avaliativo do SINAES instaurado pela Portaria Normativa ${ }^{\circ}$ 1, de 2007.

BRASIL. Portaria Normativa $\mathbf{n}^{\mathbf{0}} \mathbf{1 2}$, de 5 de setembro de 2008. Institui o Índice Geral de Cursos da Instituição de Educação Superior (IGC).

BRASIL. Resolução $\mathbf{n}^{0}$. 02, de 07 de abril de 1998. Estabelece indicadores para comprovar a produção intelectual institucionalizada, para fins de credenciamento. Brasília, DF.

DIAS SOBRINHO, José. Avaliação institucional: marco teórico e campo político. In: Avaliação da educação superior. Rio de Janeiro: Vozes, 2000. p. 89-109.

FELIX, Glades Tereza. Reconfiguração dos modelos de universidade pelos formatos de avaliação: efeitos no Brasil e Portugal. 2008. Tese (Doutorado) - Faculdade de Educação da Universidade Federal do Rio Grande do Sul, Porto Alegre, 2008.

FONSECA, Denise Grosso da Fonseca. Implicações do exame nacional de desempenho dos estudantes (ENADE) nos processos avaliativos internos do curso de educação física do IPA. 2007. Tese (Doutorado) - Programa de Pós-graduação em Educação da Universidade do Vale do Rio dos Sinos, Porto Alegre, 2007.

INSTITUTO NACIONAL DE ESTUDOS E PESQUISAS EDUCACIONAIS ANISIO TEIXEIRA (INEP). Resumo técnico do exame nacional de cursos. Brasília, DF, 2003. 
INSTITUTO NACIONAL DE ESTUDOS E PESQUISAS EDUCACIONAIS ANISIO TEIXEIRA (INEP). Censo da educação superior. Brasília, DF, 2004.

INSTITUTO NACIONAL DE ESTUDOS E PESQUISAS EDUCACIONAIS ANISIO TEIXEIRA (INEP). Censo da educação superior. Brasília, DF, 2007.

NEAVE, Guy; VAN VUGHT, Frans. Government and higher education relationships accross three continents, the winds of change. London: Pergamon Press, 1994.

ORGANIZAÇÃO DAS NAÇÕES UNIDAS PARA A EDUCAÇÃO, A CIÊNCIA E A CULTURA. UNESCO. La educacion superior em el siglo XXI: vision y acción. In: CONFERENCIA MUNDIAL SOBRE A EDUCAÇÃO SUPERIOR, 1998, Paris. Catálogo n. 135336. Curitiba, UFPR, 1998.

ORGANIZAÇÃO PARA COOPERAÇÃO ECONÔMICA E DESENVOLVIMENTO (OCDE). Education at a glance 2007. Disponível em: <www.ocde.org.br>. Acesso em: 06 jun. 2008.

POLIDORI, Marlis Morosini et al. Um olhar sobre a avaliação num contexto multidisciplinar. In: Anais do Seminário de Pesquisa em Educação da Região Sul: Pesquisa e Inserção Social, (Anpedsul), 7, 2008, Itajaí. Anais... Itajaí: Univali, 2008.

POLIDORI, Marlis Morosini; MARINHO-ARAUJO, Claisy Maria; BARREYRO, Gladys Beatriz. SINAES: perspectivas e desafios na avaliação da educação superior brasileira. ENSAIO: Avaliação de políticas públicas em educação. Rio de Janeiro: Fundação Cesgranrio, 2006. p. 425-436.

POLIDORI, Marlis Morosini. Avaliação do ensino superior: uma visão e uma análise comparativa entre os contextos brasileiro e português. 2001. Tese (Doutorado) - Faculdade de Psicologia e Ciências da Educação da Universidade do Porto, Porto, 2001.

RIBEIRO, Célia Maria; COSTA, Eula Maria de Melo B. Avaliação institucional: o desenvolvimento humano enquanto percurso e destino. Avaliação, Campinas; Sorocaba, v. 7, n. 4, p. 165-175, dez. 2002. 